\title{
Model-Free automatic segmentation of the aortic valve in multislice computed tomography images
}

\section{Aort kapakçığının çok-kesitli bilgisayarlı tomografi görüintülerinden model-bağimsiz otomatik bölüitlenmesi}

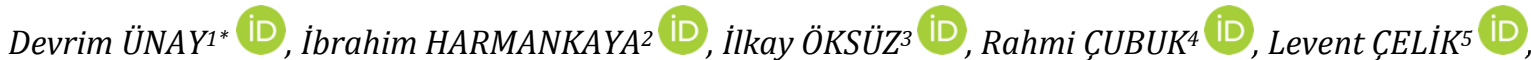 \\ Kamuran KADIPAŞAOĞLU ${ }^{6}$ (D)
}

${ }^{1}$ Electrical-Electronics Engineering, Faculty of Engineering, Izmir Democracy University, Izmir, Turkey. unaydevrim@gmail.com

2,3Electrical and Electronics Engineering, Faculty of Engineering, Bahcesehir University, Istanbul, Turkey. i.harmankaya@yahoo.com, oksuzilkay@gmail.com

${ }^{4}$ Department of Radiology, Faculty of Medicine, Maltepe University, Istanbul, Turkey. rahmicubuk@gmail.com

5Radyoloji Online Medical Imaging Services Inc., Istanbul, Turkey. leventcelik@hotmail.com

${ }^{6}$ Biomedical Engineering, Electrical-Electronics Faculty, Yıldız Technical University, Istanbul, Turkey. kamuran@yildiz.edu.tr

\begin{abstract}
Valvular diseases may affect one or more of the cardiac valves, which may need to be replaced or restored for effective treatment. The surgical procedure can be guided by a patient-specific and dynamic model containing information complementary to the $2 \mathrm{D} / 3 \mathrm{D}$ static images of the valves. To this end, in this study a novel automated model-free aortic valve segmentation method is presented, and its performance is evaluated against expert annotations over conventional contrastenhanced ECG-gated multislice CT data of the aortic valve at its closed position. Detailed evaluation of the proposed method in 19 real cases revealed an encouraging performance of $3 D$ region growing over Hessian based approach but also demonstrated the complexity of the problem.
\end{abstract}

Keywords: Aortic valve, Segmentation, Model-Free, Region growing, Hessian, Supravalvular sinus detection, Ascending aorta, Computed tomography, Valvular heart diseases.

\section{Introduction}

Heart disease is the leading cause of death in the Western world. Mortality is close to $2 \%$ in primary valvular disease, where one or more of the four cardiac valves (particularly the aortic and mitral) is affected. Roughly $2.5 \%$ of the world population acquires some form of symptomatic aortic valve diseases regardless of age [1].

Invasive interventional treatment of valvular disease consists of replacement or restoration of the affected valve(s) and, in either case, pre-operative planning and procedural outcome are greatly affected by the resolution and accuracy of the diagnostic information. However, capturing intricate anatomic detail of highly dynamic cardiac sub-structures, such as the valves and chordae, can be challenging, particularly when diagnostic images are processed with conventional techniques. Either 3-D topographic information is sacrificed when dynamic
Öz

Bir veya birden fazla kalp kapakçığının etkilenebildiği kapakçık hastalıklarının etkin tedavisi için bu kapakçkların onarılması ya da değiştirilmesini gereklidir. Kapakçıkların 2B/3B statik görüntülerinden elde edilecek bilgiyi tamamlayıcı bilgi içeren hastaya-özgü ve dinamik bir model bu girişimsel tedavi rehberlik edebilir. Bu amaçla bu çalıșmada yeni bir otomatik model-bağımsız aort kapakçığı bölütleme yöntemi önerilmiş ve yöntemin doğruluğu aort kapakçığının kapalı anına ait geleneksel kontrastlı EKG-güdümlü çok-kesitli BT verisinden elde edilen uzman ișaretlemeleri ile ölçülmüștür. Yöntemin bașarısı 19 gerçek veride detaylı olarak değerlendirilmiş ve Hessian temelli sonucun üzerine bölge büyütme yaklașımının performansının umut vadettiği ama bunun yanı sıra problemin zorluğunu göstermiştir.

Anahtar Kelimeler: Aort kapakçı̆̆ı, Bölütleme, Model-Bağımsız, Bölge büyütme, Hessian, Supravalvüler sinüs tespiti, Çılkan aort, Bilgisayarlı tomografi, Kalp kapakçı̆̆ı hastalıkları.

${ }^{*}$ Corresponding author/Yazışılan Yazar

2-D images are viewed, or functional detail is left out from highresolution 3-D anatomic renderings. There is an evident need for a diagnostic tool, which can offer both 3-D and dynamic images of the heart, particularly of the intra-cardiac structures, in a patient-specific and real-time setting. Such a 4-D model (3 dimensions in space and an additional fourth in time) will provide the interventionalist the possibility to carry out a detailed and more accurate pre-operative planning of the subsequent surgical procedure.

When the "first-in-line" ultrasound examination proves technically difficult due to patient anatomy and/or data it provides do not match the clinical picture, evaluations of diagnostic accuracy of multislice CT in valvular disorders (such as aortic valve stenosis) with respect to ultrasound is advocated [2],[3]. Accordingly cardiac image segmentation with CT has been a popular research area, where initial methods included mostly semi-automated solutions [4],[5] 
while recent studies benefit from the popular deep learning based solutions [6],[7]. In view of the valvular structures, several studies have proposed machine learning based algorithms for segmentation of the tract, but ignored valvular segmentation [8]-[10]. More recently proposed solutions include fully automated approaches that make use of virtual heart models for improved segmentation [11]-[18]. However state-of-the-art automated segmentation of valvular structures, and specifically of the aortic valve, is limited. This is a relatively less-studied problem and, to our knowledge, there exist only a few works on automated aortic valve segmentation from computed tomography (CT) images, all of which have taken advantage of 4D models generated from CT data [19]-[22].

Preoperative assessment of patients with aortic stenosis (AS), the most common valvular disease, requires evaluation of AS severity via segmenting the valve with ultrasound (US) data, accepted as diagnostic standard; and measuring the aortic valve area (AVA). Recent research efforts focused on the feasibility and accuracy of contrast-enhanced multidetector computed tomography (CT) for this task. Feuchtner et al. [3] manually traced the aortic valve on CT and US scans of 46 subjects, and compared the AVA to show the reliability of CT for identification of patients with degenerative AS. Their results showed that CT is $100 \%$ sensitive for identification of patients with AS. Furthermore, mean AVA on CT data is measured as $0.94 \mathrm{~cm}^{2}$, and showed good correlation with US data. In another study [23], the aortic valve is manually segmented on CT and US scans of 40 subjects, and the mean AVA are measured respectively as 0.87 and $0.81 \mathrm{~cm}^{2}$ indicating good correlation between the two modalities.

Besides these manual approaches, automated segmentation of the aortic valve is an under-investigated topic with only a few solutions proposed. Ionasec et al. [19] presented a discriminative learning-based method to generate a physiological model of the aortic valve using splines together with anatomically-driven topological and geometrical constraints. They evaluated their method on CT scans of 37 subjects and reported a mean Bland-Altman systematic bias of $0.12 \mathrm{~cm}^{2}$ indicating high agreement between expert annotated and model-based AVA measurements. Weese et al. [21] introduced a study on generating patient-specific heart models by adapting generic models to the patient data (16 contrastenhanced CT scans used for the valve model). Adaptation of the model to the patient data is achieved by generalized Hough transform-based organ localization, and iterative application of appearance-based boundary detection and linear transformations. The accuracy of model adaptation for aortic valve is measured by symmetrized mean Euclidean "surface-topatch" distance as $0.47 \mathrm{~mm}$. Liang et al. [24] developed a machine learning based method to automatically reconstruct 3D geometry of the aortic valve from 3D CT images, and employed this reconstructed geometry for finite element modelling to simulate aortic valve closure. The average landmark detection error of their approach over $10 \mathrm{CT}$ scans is measured as $2.17 \mathrm{~mm}$.

Simultaneous segmentation of multiple cardiac valves is a far less studied topic mainly due to the difficulty of the problem. In an early semi-automatic work [25], cardiac valves are manually segmented on CT images and the corresponding 3D polygon models are generated via marching cubes algorithm using an in-house software. Then, a commercial software is used to fit a 3D NURBS surface to the polygon model at each time frame. Unfortunately, the accuracy of the final valve model is not evaluated. More recently, Ionasec et al. [20] introduced an automatic, hierarchical learning-based method to capture patient-specific models of the aortic and mitral valves. Evaluation of the proposed method is performed on a heterogeneous set (1516 US and 690 CT scans from 134 subjects), and the average accuracies are measured as 1.54 and $1.36 \mathrm{~mm}$ for the US and CT data sets, respectively. Grbic et al. [22] employed a patient-specific 4D CT heart valves model in a disciminative learning framework to segment all four cardiac valves. Their approach achieved average errors in the range of 1.22-1.40 mm over 64 cardiac CT volumes.

Above reports reveal that segmentation of the aortic valve from CT images is a challenging task, where the proposed solutions are mostly based on either manual delineations or automatically deforming a pre-constructed valvular model (Table 1). In the present study a novel method for the automated model-free segmentation of the aortic valve in its closed position using conventional contrast-enhanced ECGgated multislice CT data is presented. Performance of the proposed method is evaluated on a CT database of real cases acquired at the Maltepe University Hospital.

\section{Materials and methods}

In this study, aortic valve segmentation is accomplished on the traditionally used cardiac planes (horizontal and vertical long axes and short axis) (Figure 1) by successively applying 1) contrast-enhanced region detection through histogram analysis, 2) circle fitting- and region growing-based ascending aorta detection, 3) supravalvular sinus detection using shape constraints, and 4) three-dimensional (3D) region growing over Hessian based aortic valve segmentation.

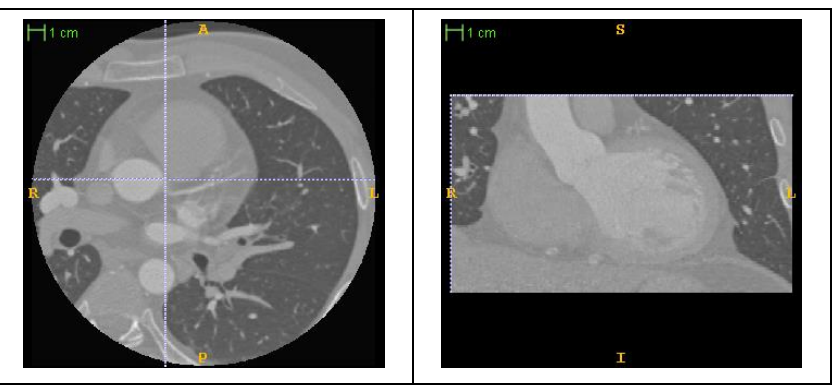

Figure 1. Typical horizontal (left) and vertical long axes images from the database.

\subsection{Subjects and Image data}

The database employed in this study consists of 55 contrastenhanced ECG-gated 3D cardiac CT volumes, which are acquired from multiple patients suspected to suffer from various cardiovascular diseases (such as coronary artery diseases and stroke) at the Maltepe University Hospital. Ethical committee approval was secured prior to the study. Written informed consent was obtained from all subjects. The acquisition parameters were as follows: capture range varying from 108 to 220 slices, slice thickness of $1 \mathrm{~mm}$, image matrix of $512 \times 512$ pixels, and in-plane resolution of $0.39 \mathrm{~mm}$.

\subsection{Histogram-based contrast enhanced region detection}

Our observations revealed that intensity ranges of contrastenhanced regions vary largely between scans of different subjects (Figure 2), and therefore fixed thresholding does not yield reliable results. 
Table 1. Summary of literature on segmentation and analysis of valvular structures. CT: Computed Tomography, MRI: Magnetic Resonance Imaging, US: Ultrasound, NA: Not Available, AVA: Aortic Valve Area.

\begin{tabular}{|c|c|c|c|c|c|}
\hline Work & Valve-of-interest & Modality & Segmentation method & Dataset & Quantitative evaluation \\
\hline $\begin{array}{l}\text { Feuchtner et al. } \\
2006[3]\end{array}$ & Aortic & CT, US & Manual & $\begin{array}{c}46 \text { subjects } \\
\text { (30 with aortic stenosis) }\end{array}$ & $\begin{array}{c}\text { Mean AVA (CT): } .94 \mathrm{~cm}^{2}, \text { good } \\
\text { correlation with US. }\end{array}$ \\
\hline $\begin{array}{l}\text { Laissy et al. } \\
2007 \text { [23] }\end{array}$ & Aortic & CT, US & Manual & 40 subjects & $\begin{array}{c}\text { Mean AVA: } .87 \mathrm{~cm}^{2}(\mathrm{CT}), \\
.81 \mathrm{~cm}^{2} \text { (US) }\end{array}$ \\
\hline $\begin{array}{l}\text { Ionasec et al. } \\
2008 \text { [19] }\end{array}$ & Aortic & CT & $\begin{array}{l}\text { Automatic } \\
\text { Hierarchical, learning based } \\
\text { model estimation and fitting }\end{array}$ & $\begin{array}{l}37 \text { subjects }(364 \mathrm{CT} \\
\text { scans) }\end{array}$ & Mean AVA: $.12 \mathrm{~cm}^{2}$ \\
\hline $\begin{array}{l}\text { Weese et al. } \\
2010[21]\end{array}$ & Aortic & CT, MRI & $\begin{array}{c}\text { Automatic } \\
\text { Appearance based boundary } \\
\text { detection and model fitting }\end{array}$ & Heart model: 35 CT scans & $\begin{array}{c}\text { "Surface-to-patch" distance: } \\
.47 \mathrm{~mm}\end{array}$ \\
\hline $\begin{array}{l}\text { Liang et al. } \\
2017[24]\end{array}$ & Aortic & $\mathrm{CT}$ & $\begin{array}{c}\text { AutomaticMachine learning } \\
\text { based }\end{array}$ & 10 CT scans & $\begin{array}{l}\text { Mean "landmark" detection } \\
\text { error: } 2.17 \mathrm{~mm}\end{array}$ \\
\hline $\begin{array}{l}\text { Segars et al. } \\
2007 \text { [25] }\end{array}$ & All cardiac valves & CT & $\begin{array}{l}\text { Semi-automatic } \\
\text { Marching cubes and model } \\
\text { fitting }\end{array}$ & NA & NA \\
\hline $\begin{array}{l}\text { Ionasec et al. } \\
2010[20]\end{array}$ & Aortic, mitral & CT, US & $\begin{array}{l}\text { Automatic } \\
\text { Hierarchical, learning based } \\
\text { model estimation and fitting }\end{array}$ & $\begin{array}{l}134 \text { subjects ( } 690 \mathrm{CT} \\
\text { scans, } 1516 \text { US scans }\end{array}$ & $\begin{array}{l}\text { Mean "landmark" detection } \\
\text { error: } 1.54 \text { (US) and } 1.36 \\
\text { (CT) mm }\end{array}$ \\
\hline $\begin{array}{l}\text { Grbic et al. } \\
2012[22]\end{array}$ & All cardiac valves & CT & $\begin{array}{c}\text { Automatic } \\
\text { Discriminative learning based } \\
\text { model fitting }\end{array}$ & 64 CT scans & $\begin{array}{l}\text { Mean "landmark" detection } \\
\text { error: } 1.22 \mathrm{~mm}\end{array}$ \\
\hline
\end{tabular}

As contrast-enhanced regions correspond to the brightest locations on a CT scan (and thus to the highest peak in the histogram), the detection of these regions is realized by locating the center of the highest peak in the histogram, and hysteresis thresholding with the least of $25 \%$ or \pm 150 of the center value (Figure 3). The result is then refined by applying morphological operations to fill gaps and remove small isolated regions (Figure 4).

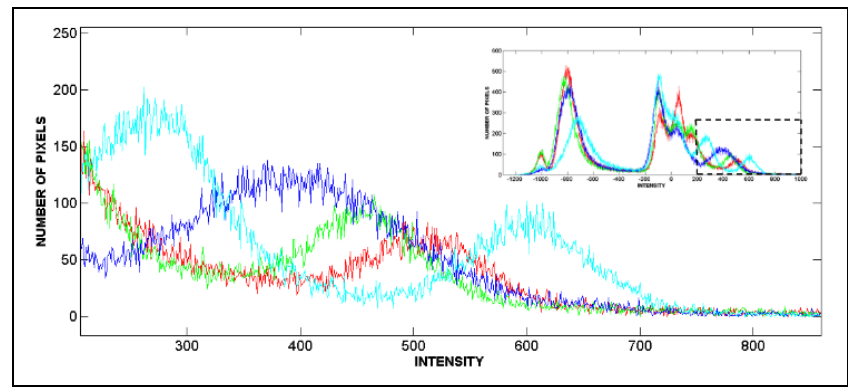

Figure 2. Histograms of multiple subjects' data included in the study in normal (top-right) and zoomed views. Notice the large variance in the intensity of contrast-enhanced regions within the database.

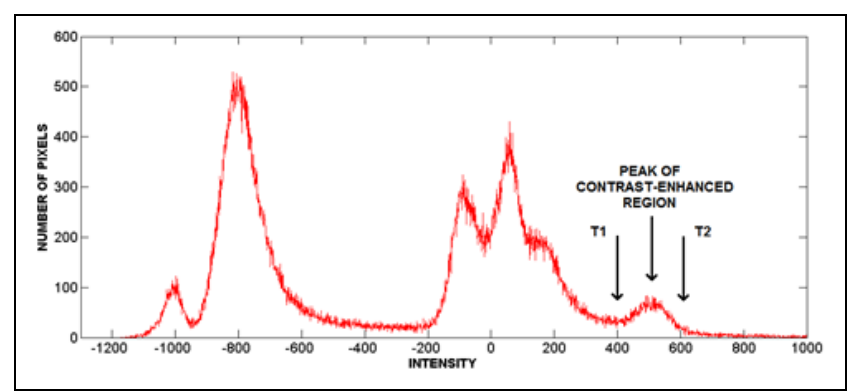

Figure 3. Histogram of a single-subject data depicting the peak, and the lower (T1) and higher (T2) thresholds detected.

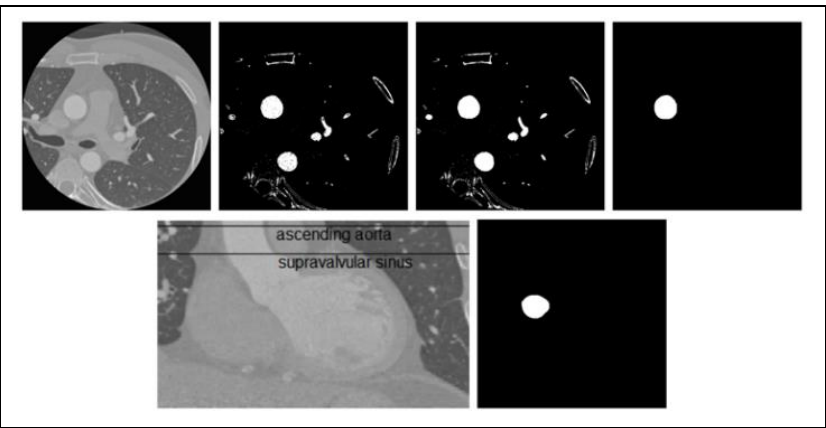

Figure 4. Visual examples of the proposed supravalvular sinus detection method. Top row, left-to-right: Original horizontal long axis image corresponding to the candidate ascending aorta, result of histogram-based contrast-enhanced region detection, result of morphological filtering, and result of ascending aorta detection using circle fitting. Bottom row: vertical long axis image showing slice levels corresponding to the candidate ascending aorta and supravalvular sinus (left), and the segmentation result of the aorta at the supravalvular sinus location.

\subsection{Segmentation of ascending aorta}

The aorta is a quasi-circular cylindrical tube, and the ascending aorta is greater in diameter than its descending counterpart [26]. Accordingly, detection of the ascending aorta is realized by processing the horizontal long axis views in the caudal direction in a hierarchical fashion as follows.

First, a candidate ascending aorta region is identified by applying circle fitting on the contrast-enhanced regions found in the previous step and retaining the largest circle-like structure in the view. Then, adjacent slices (from head-to-toe) are sequentially processed towards the next segment of the ascending aorta by applying region growing with the geometric center of the previously segmented aorta region used as a seed point. Segmentation result of each slice is further refined by morphological operations to fill possible gaps and remove isolated regions (Figure 4). 


\subsection{Detection of supravalvular sinus}

For full automatization of the aortic valve segmentation from conventional CT data, the search algorithm must first detect an anatomic landmark and use it as the starting point in the subsequent search steps. The supravalvular sinus may serve as a unique marker due to its peculiar geometry which allows relatively little inter-patient variabilty.

Analyses on the horizontal long axis views disclose that, as one approaches the aortic valve starting from a distal location, the shape of the aorta deviates from its circular form and the aorta increasingly drifts from the superior-inferior orientation. Consequently, the shape change is captured by analyzing pairwise ratios of the aortic diameter measured at $0^{\circ}, 45^{\circ}, 90^{\circ}$, and $135^{\circ}$.

Finally, the supravalvular sinus detection is achieved by locating the corresponding horizontal long axis slice level, where shape change exceeds $18 \%$ (set empirically).

\subsection{Segmentation of Aortic Valve}

In order to accomplish segmentation of the aortic valve, different approaches like thresholding, 3D region growing and Hessian based approach [27] are utilized. In all approaches, segmentation is realized starting from the supravalvular sinus level towards the left ventricle in 3D, and is constrained within the ascending aorta region as previously defined. The parameters of each approach (such as the threshold for region inclusion in region growing, and scale range searched by the Hessian based approach) are set empirically to obtain the best segmentation possible.

In region growing, the inclusion criteria for a candidate voxel is based on similarity with the mean region intensity. The seed point for initialization of region growing is automatically found via histogram analysis as the lowest luminance value in the constrained region, which corresponds to the point of central leaflet coaptation.

In the Hessian based approach, a vessel enhancement filter based on the multiscale second order local structure of the image (Hessian) is computed, and a vesselness measure is obtained from the eigenvalues of the Hessian. Additionally, one can examine the eigenvectors of the Hessian to group voxels having similar gradient direction (referred to as angular similarity here). To this end, in this work we explore the segmentation performance of region growing applied on vesselness only, vesselness $x$ original image, and vesselness $x$ angular similarity.

\subsection{Performance evaluation}

Quantitative performance evaluation of the proposed method is realized based on two criteria: (1) supravalvular sinus detection, and (2) segmentation of the aortic valve. For the former, location in each CT scan of the dataset was visually identified (in 3D) by two experts based on consensus agreement. These manually identified locations are then compared with those automatically found by the proposed method, and the Euclidean difference (in $\mathrm{mm}$ ) between the two measurements is reported. In the latter, aortic valve leaflets in CT scans of nineteen subjects were manually delineated by the same experts in order to assess aortic valve segmentation accuracy. The 3D CT scans correspond to the cardiac phase showing maximal aortic valve closure. The nineteen subjects were selected to provide a challenging test set that reflects diverse pathological, anatomical, and image acquisition related variations (e.g. five subjects had normal functioning aortic valves, while the others had undergone valvular repair, bypass, and aneurysm surgeries).

Quantitative evaluation of aortic valve segmentation is realized by comparing manual and automated results, and reported by

$$
\begin{aligned}
\text { Dice overlap score } & =\frac{2 \times T P}{F P+2 \times T P+F N} \\
\text { Precision } & =\frac{T P}{T P+F P} \\
\text { Recall } & =\frac{T P}{T P+F N}
\end{aligned}
$$

where $T P, F P$ and $F N$ correspond to the total number of true positives, false positives, and false negatives, respectively. Ideally all three measures having high scores reflect better segmentation. In both evaluation stages, the data utilized for testing (20 for supravalvular sinus detection and 19 for aortic valve segmentation) were excluded from the training set (31 for supravalvular sinus detection and 36 for aortic valve segmentation) used to optimize the method.

\section{Results}

We first demonstrate the performance of the proposed supravalvular sinus detection algorithm on 20 contrastenhanced ECG-gated 3D cardiac CT volumes, which were acquired from multiple patients suspected to suffer from various cardiovascular diseases. The proposed supravalvular sinus detection method achieved an absolute error (in $\mathrm{mm}$ ) of $0.81 \pm 0.79$ and $1.25 \pm 1.12$ (average \pm standard deviation) for the training and the test sets, respectively. Figure 5 presents the errors per case, where a zero-error rate is attained for most cases both in training and test sets. In a single case, the method misses the supravalvular sinus by large ( $4 \mathrm{~mm}$ error for Case 17 of the test set).

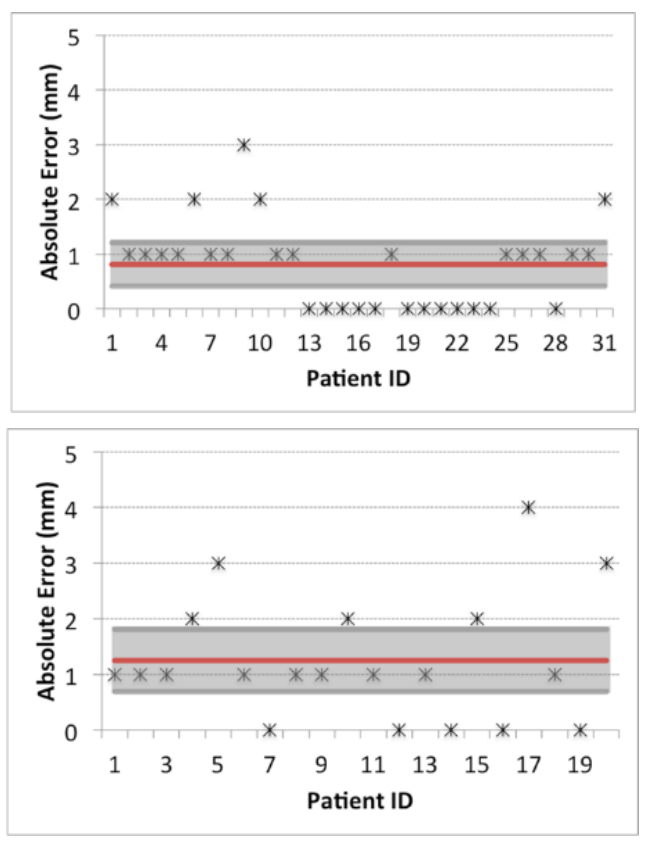

Figure 5. Absolute errors of the proposed supravalvular sins detection method for the training (top) and test sets. In each graph, solid red lines indicate mean errors, while shaded areas correspond to mean \pm standard deviation $/ 2$. 
Following supravalvular sinus detection, we demonstrate the performance of the proposed aortic valve segmentation methods. First, the effect of constraining the region growing on Hessian based segmentation method with the automatically extracted aortic region is evaluated (Figure 6), where constraining the segmentation method with the aort mask considerably improves the segmentation performance (average Dice score improves by more than 50\%).

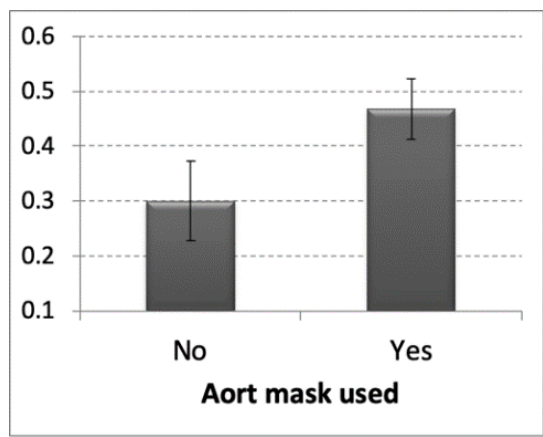

Figure 6. Effect of constraining the segmentation with aort mask. Average Dice scores for the segmentation results of the proposed method with and without the aort mask are measured as 0.468 and 0.301 , respectively. Error bars represent one standard deviation.

Figure 7 shows the performances of all three methods constrained with the aort mask: 1) thresholding of Hessian based outcome, 2) region growing on original image, and 3) region growing on Hessian based outcome. Both visual and quantitative evaluations via Dice score have shown that highest segmentation accuracy is achieved by the proposed region growing on Hessian based outcome (average Dice score $=0.468$ ), whereas the worst performance belongs to the method of thresholding Hessian based outcome (average Dice score $=0.108)$.

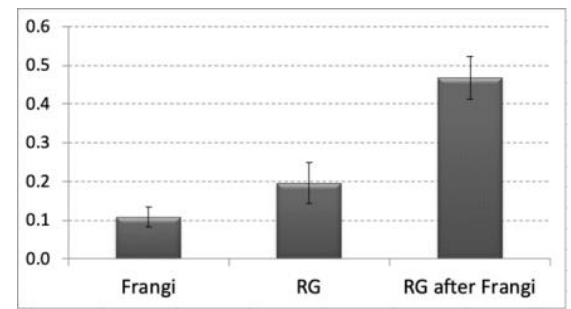

Figure 7. Performance comparison of all methods measured via Dice overlap score with manual segmentations. RG refers

to region growing. Error bars represent one standard deviation.

The segmentation performance of the best method (region growing applied on Hessian based outcome and constrained with the aort mask) is evaluated on the data of nineteen test subjects using precision and recall measures, and demonstrated in Figure 8. Average precision and recall values are measured as .694 and .369, respectively. Highest scores attain .55 recall and .70 precision values (two rightmost datapoints in the figure), while the lowest ones (two bottommost datapoints) exhibit precision figures less than .5 mainly due to the lower contrast between the valvular region and the surrounding bood-filled (contrast-enhanced) inner aorta.

Figure 9 presents typical segmentation results of the best method overlaid on original images and displayed in comparison to the manual segmentations. As compared to the manual delineations, the automated method can lead to promising overall segmentation results in some cases (e.g. left and center columns), whereas it can result in undersegmentation and only partially capture the leaflets in others (e.g. right column and the upper-right leaflet in center column). Nevertheless, it is worth to note that the proposed segmentation method generally does not leak out of the leaflet region.

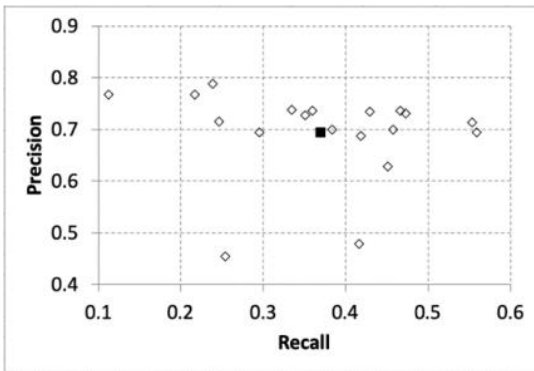

Figure 8. Performance evaluation of the proposed method over nineteen test subjects demonstrated via precision-recall scatter matrix. Average over all subjects is marked with a square.

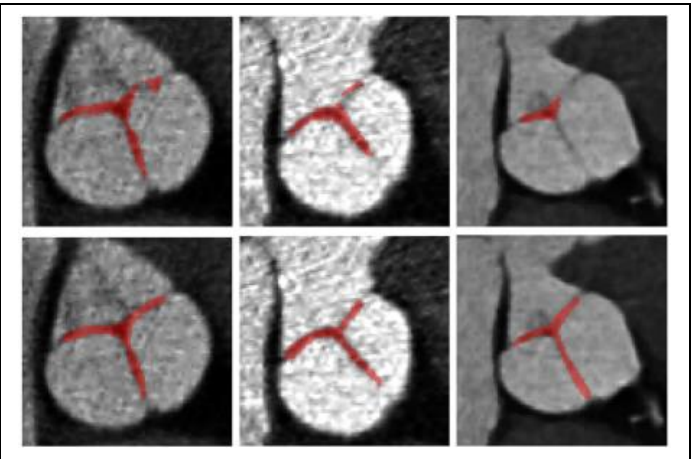

Figure 9. Typical segmentation results achieved by the proposed region growing on Hessian based outcome (constrained with the aort mask) method displayed together with the corresponding manual delineations (bottom row).

Segmentations are overlaid on original CT scans and appropriately cropped for better visualization.

Finally, we demonstrate the segmentation performance of the proposed method relative to manual delineation in terms of surface mesh representation for a single subject data (Figure 10). As observed, the proposed method results in a valve model with consistent topology - despite slightly thicker leaflets and subtle differences in the roots (notice the missing part at the root of the leaflet on the left) - as compared to manual delineation.
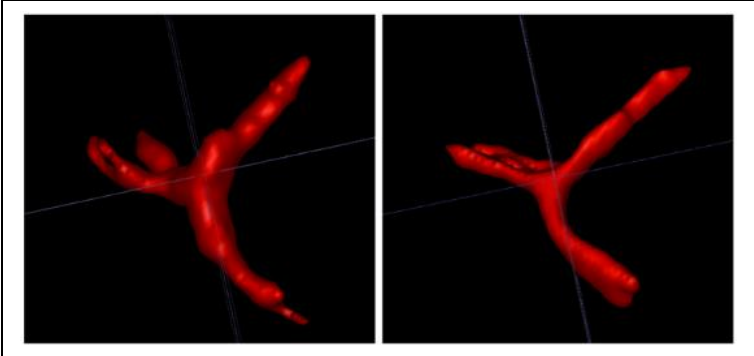

Figure 10. Surface meshes built from automated (left) and manual segmentation results for a single subject. Meshes are appropriately oriented and cropped for better visualization. 


\section{Discussion}

This work presents a novel automated model-free method for segmenting aortic valve in its closed position from conventional contrast-enhanced ECG-gated multislice CT data. The proposed method successively applies 3D histogram analysis based contrast-enhanced region detection, ascending aorta detection using circle fitting and region growing, supravalvular sinus detection via shape constraints, and 3D region growing over Hessian based outcome constrained in the ascending aorta.

The performance is evaluated on real CT images based on two criteria: 1) supravalvular sinus detection, and 2) segmentation of the aortic valve. Experimental results show that the method is highly accurate in the former, while less precise in the latter mainly due to the low contrast between the valve area and the neighboring tissue. Regarding supravalvular sinus detection, the method achieves an average (absolute) error rate of $1.25 \mathrm{~mm}$, which is better than [20],[24] or almost at par [22] with the state-of-the-art. Case-by-case investigation of the results reveals that most errors are at the $\pm 1 \mathrm{~mm}$ range, while only a single case exhibits a large error $(4 \mathrm{~mm})$ due to the coarse measurement of shape change in the supravalvular sinus detection step. This can be overcome by measuring shape change at a finer angular resolution or using a more generic approach such as the compactness measure.

Regarding aortic valve segmentation, comparative evaluations show that applying 3D region growing over Hessian based result and constraining the segmentation within the ascending aorta gives the most accurate results as compared to the stateof-the-art solutions such as region growing over original images. On the nineteen real cases accuracy of the proposed method is observed to be promisingly high (average Dice score superior to. 46), while in two cases inaccurate segmentation is achieved due to the lower contrast between the valvular region and the surrounding bood-filled inner aorta. Performance comparison of the proposed aortic valve segmentation method with the state-of-the-art is difficult, because the studies in the literature (e.g. [3],[23]) generally include manual segmentation only and report just the mean aortic valve area values without any overlap measure like the Dice score.

The proposed work was part of a research project where the aim is to segment and model valvular structures from 4D cardiac CT data. The output of the aortic valve segmentation method proposed here can therefore be extended for segmenting full cardiac cycle CT sequences. Besides, we believe the performance of the proposed automated aortic valve segmentation method will be improved if 1) better representation of higher resolution imaging data were in use (such as employing oblique slices at the valve plane via multiplanar reformatting), and 2) an aortic valve model were exploited. Lastly, reliability of the proposed method should further be evaluated on a larger cohort and validated against the state-of-the-art imaging modalities used in clinical settings, such as ultrasound.

\section{Author contribution statements}

In the scope of this study, Devrim Ünay contributed to the ideation, design of image processing methods and algorithms, supervision of the implementation and the validation stages, literature review, analysis of results, writing and revision of the article. İbrahim Harmankaya contributed to the literature review, implementation of the image processing methods and algorithms and their evaluation on the data, revision of the article. İlkay Öksüz contributed to the literature review, implementation of the image processing methods and algorithms and their evaluation on the data, revision of the article. Rahmi Çubuk contributed to the selection and inclusion of the patients to the study, acquisition and annotation of image data, revision of the article. Levent Çelik contributed to the selection and inclusion of the patients to the study, acquisition and annotation of image data, revision of the article. Kamuran Kadıpaşaoğlu contributed to the establishment of communication between the technical and clinical teams and clarification of the general design of the study from technicalclinical aspects, revision of the article.

\section{Ethics committee approval and conflict of interest statement}

There is no need to obtain permission from the ethics committee for the article prepared.

There is no conflict of interest with any person / institution in the article prepared.

\section{References}

[1] Lloyd-Jones D, Adams RJ, Brown TM, Carnethon M, Dai S, De Simone G, Ferguson TB, Ford E, Furie K, Gillespie C, Go A, Greenlund K, Haase N, Hailpern S, Ho PM, Howard V, Kissela B, Kittner S, Lackland D, Lisabeth L, Marelli A, McDermott MM, Meigs J, Mozaffarian D, Mussolino M, Nichol G, Roger VL, Rosamond W, Sacco R, Sorlie P, Stafford R, Thom T, Wasserthiel-Smoller S, Wong ND, Wylie-Rosett J. "Executive summary: heart disease and stroke statistics-2010 update". Circulation, 121(7), 948-954, 2010.

[2] Bouvier E, Logeart D, Sablayrolles JL, Feignoux J, Scheublé C, Touche T, Thabut G, Cohen-Solal A. "Diagnosis of aortic valvular stenosis by multislice cardiac computed tomography". European Heart Journal, 27(24), 3033-3038, 2006.

[3] Feuchtner GM, Dichtl W, Friedrich GJ, Frick M, Alber HF, Schachner T, Bonatti JO, Mallouhi A, Frede T, Pachinger O, Nedden DZ, Mueller S. "Multislice computed tomography for detection of patients with aortic valve stenosis and quantification of severity". Journal of the American College of Cardiology, 47(7), 1410-1417, 2006.

[4] Frangi AF, Niessen WJ, Viergever MA. "Three-Dimensional modeling for functional analysis of cardiac images: A review". IEEE Transactions on Medical Imaging, 20(1), 2-25, 2001.

[5] Frangi AF, Rueckert D, Duncan JS, "Three-Dimensional cardiovascular image analysis". IEEE Transactions on Medical Imaging, 21(9), 1005-1010, 2002.

[6] Payer C, Štern D, Bischof H, Urschler M. "Multi-label whole heart segmentation using CNNs and anatomical label configurations". Lecture Notes in Computer Science, 10663, 190-198, 2018.

[7] Xu Z, Wu Z, Feng J. “CFUN: Combining faster R-CNN and Unet network for efficient whole heart segmentation". arXiv, 2018. https://arxiv.org/pdf/1812.04914.pdf .

[8] Zheng Y, John M, Liao R, Nottling A, Boese J, Kempfert J, Walther T, Brockmann G, Comaniciu D. "Automatic aorta segmentation and valve landmark detection in C-Arm CT for transcatheter aortic valve implantation". IEEE Transactions on Medical Imaging, 31(12), 2307-2321, 2012. 
[9] Queirós S, Papachristidis A, Morais P, Theodoropoulos K, Fonseca J, Monaghan M, Vilaça J, D'hooge J. "Fully automatic 3-D-TEE segmentation for the planning of transcatheter aortic valve implantation". IEEE Transactions on Biomedical Engineering, 64(8), 1711-1720, 2017.

[10] Elattar MA, Wiegerinck E, Planken R, Vanbavel E, van Assen H, Baan J, Marquering H. "Automatic segmentation of the aortic root in CT angiography of candidate patients for transcatheter aortic valve implantation". Medical and Biological Engineering and Computing, 52(7), 611-618, 2014.

[11] Lorenzo-Valdés M, Sanchez-Ortiz GI, Mohiaddin R, Rueckert D. "Segmentation of 4D cardiac MR images using a probabilistic atlas and the EM algorithm". Lecture Notes in Computer Science, 2878, 440-450, 2003.

[12] Fritz D, Rinck D, Unterhinninghofen R, Dillmann $R$, Scheuering M. "Automatic segmentation of the left ventricle and computation of diagnostic parameters using regiongrowing and a statistical model". Proceedings of SPIE Medical Imaging, 5747, 1844-1851, 2005.

[13] Ecabert 0, Peters J, Weese J. "Modeling shape variability for full heart segmentation in cardiac computedtomography images". Proceedings of SPIE Medical Imaging, 6144, 1-8, 2006

[14] Lynch M, Ghita O, Whelan PF. "Left-ventricle myocardium segmentation using a coupled level-set with a priori knowledge". Computerized Medical Imaging and Graphics, 30(4), 255-262, 2006.

[15] Zheng Y, Barbu A, Georgescu B, Scheuering M, Comaniciu D. "Four-chamber heart modeling and automatic segmentation for 3-D cardiac CT volumes using marginal space learning and steerable features". IEEE Transactions on Medical Imaging, 27(11), 1668-1681, 2008.

[16] Lin X. Model-Based Strategies for Automated Segmentation of Cardiac Magnetic Resonance İmages. PhD Thesis, University of Auckland, New Zealand, 2008.

[17] Dong B, Guo Y, Wang B, Gu L. "Aortic valve segmentation from ultrasound images based on shape constraint CV model". Proceedings of the Annual International Conference of the IEEE Engineering in Medicine and Biology Society, Osaka, Japan, 3-7 July 2013.

[18] Pouch AM, Wang H, Takebe M, Jackson B, Sehgal C, Gorman III J, Gorman R, Yushkevich P. "Automated segmentation and geometrical modeling of the tricuspid aortic valve in 3D echocardiographic images". Lecture Notes in Computer Science, 8149, 485-492, 2013.
[19] Ionasec RI, Georgescu B, Gassner E, Vogt S, Kutter O, Scheuering M, Navab N, Comaniciu D. "Dynamic modeldriven quantitative and visual evaluation of the aortic valve from 4D CT". Lecture Notes in Computer Science, 5241, 686-694, 2008.

[20] Ionasec RI, Voigt I, Georgescu B, Wang Y, Houle H, Higuera F, Navab N, Comaniciu D. "Patient-specific modeling and quantification of the aortic and mitral valves from 4-D cardiac CT and TEE". IEEE Transactions on Medical Imaging, 29(9), 1636-1651, 2010.

[21] Weese J, Peters J, Meyer C, Wächter I, Kneser R, Lehmann H, Ecabert O, Barschdorf H, Hanna R, Weber FM, Dössel O, Lorenz C. "The generation of patient-specific heart models for diagnosis and interventions". Lecture Notes in Computer Science, 6364, 25-35, 2010.

[22] Grbic S, Ionasec R, Vitanovski D, Voigt I, Wang Y, Georgescu B, Navab N, Comaniciu D. "Complete valvular heart apparatus model from 4D cardiac CT". Medical Image Analysis, 16(5), 1003-1014, 2012.

[23] Laissy JP, Messika-Zeitoun D, Serfaty JM, Sebban V, Schouman-Claeys E, Iung B, Vahanian A. “Comprehensive evaluation of preoperative patients with aortic valve stenosis: Usefulness of cardiac multidetector computed tomography". Heart, 93(9), 1121-1125, 2007.

[24] Liang L, Kong F, Martin C, Pham T, Wang Q, Duncan J, Sun W. "Machine learning-based 3-D geometry reconstruction and modeling of aortic valve deformation using 3-D computed tomography images". International Journal for Numerical Methods in Biomedical Engineering, 33(5), 1-13, 2017.

[25] Segars WP, Mendonca S, Sturgeon G, Tsui BMW. "Enhanced 4D heart model based on high resolution dual source gated cardiac CT images". IEEE Nuclear Science Symposium Conference Record, Honolulu, Hawaii, 28 October-3 November 2007.

[26] Boulnois JL, Pechoux T. "Non-invasive cardiac output monitoring by aortic blood flow measurement with the Dynemo 3000". Journal of Clinical Monitoring and Computing, 16(2), 127-140, 2000.

[27] Frangi AF, Niessen WJ, Vincken KL, Viergever MA. "Multiscale vessel enhancement filtering". Lecture Notes in Computer Science, 1496, 130-137, 1998. 